OPEN

SUBJECT AREAS:

MOLECULAR BIOLOGY

CELL BIOLOGY

MICROBIOLOGY

Received

28 March 2014

Accepted

1 May 2014

Published

23 May 2014

Correspondence and requests for materials should be addressed to

R.Z. (rzhang@med.

wayne.edu)

* These authors contributed equally to this work.

\section{Elevated circulating lipasin/betatrophin in human type 2 diabetes and obesity}

\author{
Zhiyao Fu' ${ }^{1 *}$, Feven Berhane ${ }^{2 *}$, Alemu Fite ${ }^{2}$, Berhane Seyoum ${ }^{2}$, Abdul B. Abou-Samra ${ }^{2,3}$ \& Ren Zhang ${ }^{1,2}$
}

${ }^{1}$ Center for Molecular Medicine and Genetics, School of Medicine, Wayne State University, Detroit, MI 48201, USA, ${ }^{2}$ Division of Endocrinology, School of Medicine, Wayne State University, Detroit, MI 48201, USA, ${ }^{3}$ Department of Medicine, Hamad Medical Corporation, Doha, Qatar.

Lipasin (also known as C19ORF80, RIFL, ANGPTL8 and betatrophin) is a newly discovered circulating factor that regulates lipid metabolism and promotes pancreatic $\beta$-cell proliferation. Whether circulating levels of lipasin in humans are altered in a) type 2 diabetes; b) obesity and c) the postprandial state, however, is unknown. The current study aimed to compare serum lipasin levels in those who were a) non-diabetic ( $\mathrm{N}$ $=15)$ or diabetic (BMI- and age-matched; $N=14) ; b)$ lean or obese $(\mathrm{N}=53$ totally) and c) fasting and 2 hours following a defined meal $(\mathrm{N}=12)$. Serum lipasin levels were determined by the enzyme-linked immunosorbent assay. Lipasin levels [mean $\pm \mathrm{SEM}$ ] were increased by more than two fold $(\mathrm{P}<0.001)$ in the diabetic patients $(5.56 \pm 0.73 \mathrm{ng} / \mathrm{mL})$ as compared to the control subjects $(2.19 \pm 0.24 \mathrm{ng} / \mathrm{mL})$. Serum lipasin levels were positively correlated with BMI (rho $=0.49, \mathrm{P}<0.001)$, and showed a $35 \%$ increase 2 hours following a defined meal $(\mathrm{P}=\mathbf{0 . 0 0 9})$. Therefore, lipasin/betatrophin is nutritionally-regulated hepatokine that is increased in human type 2 diabetes and obesity.

M etabolic syndrome is a cluster of metabolic disorders, including glucose intolerance and dyslipidemia, which increase the risk of developing atherosclerotic cardiovascular diseases and diabetes ${ }^{1}$. Prevalence of metabolic syndrome, a major public health issue, has been increasing steadily, resulting in a growing interest in developing drugs to correct dyslipidemia and hyperglycemia. Recently four groups independently characterized a novel liver-enriched and nutritionally-regulated factor, called lipasin ${ }^{2,3}$, RIFL (Re-feeding Induced in Fat and Liver) ${ }^{4}$, ANGPTL8 (angiopoietin-like protein 8) ) $^{5,6}$ and betatrophin ${ }^{7}$, which has been shown to have a dual role in both lipid metabolism and glucose homeostasis.

The official symbol for this protein is C19ORF80 (human) and Gm6484 (mouse), and here it is referred to as lipasin. Ren et al. described Gm6484 as RIFL, and showed that RIFL is highly induced during adipocyte differentiation, which is inhibited by RIFL knockdown ${ }^{4}$. Quagliarini et al. identified Gm6484 as ANGPTL8, and showed that ANGPTL8 interacts with and promotes ANGPTL3 cleavage ${ }^{5}$. ANGPTL8-null mice have impaired fatty acid uptake in white adipose tissue ${ }^{6}$. We identified lipasin as a liver-enriched nutritionally-regulated gene by using RNA-seq. Lipasin is predominantly expressed in the human liver, and its expression is suppressed by fasting, and highly induced by feeding ${ }^{2}$. Lipasin-null mice show reduced serum triglycerides ${ }^{6,8}$, while its overexpression dramatically increases serum triglycerides ${ }^{2,5}$. Lipasin likely inhibits lipoprotein lipase (LPL) activity directly $^{2}$ or indirectly by promoting ANGPTL3 cleavage, releasing the N-terminal domain, which, in turn, inhibits LPL ${ }^{5}$. Consistently, ANGPTL8-null mice had increased LPL activity ${ }^{6}$. In humans, lipasin sequence variations are associated with lipid profiles ${ }^{5,9,10}$. Lipasin is therefore an important regulator of lipid metabolism.

Yi et al. named Gm6484 as betatrophin, and showed that it is a hormone that potently promotes pancreatic $\beta$ cell proliferation ${ }^{7}$. They first infused an insulin receptor antagonist to induce compensatory $\beta$-cell mass expansion in the pancreas, and betatrophin was induced in the liver during this process. Transgenic overexpression of betatrophin in the liver induced a 17 -fold increase in the rate of $\beta$-cell proliferation. After 8 days, this increased $\beta$ cell proliferation resulted in a 3 -fold higher pancreatic $\beta$-cell area, associated with improved $\beta$-cell function, and improved glucose tolerance. Therefore, the effect of betatrophin on $\beta$-cell proliferation was robust, rapid and specific ${ }^{7}$. Indeed, serum betatrophin was recently shown to be increased in patients with type 1 diabetes ${ }^{11}$.

Despite the important roles of lipasin in regulating lipid metabolism and in promoting $\beta$-cell proliferation, whether its circulating levels in humans are altered in 1 ) type 2 diabetes; 2 ) obesity and 3 ) the postprandial state, are unknown. To address these questions, here, we have examined serum lipasin levels in BMI- and age-matched human subjects with or without type 2 diabetes, in lean and obese subjects and compared fasting and postprandial levels in human subjects following a defined meal. 

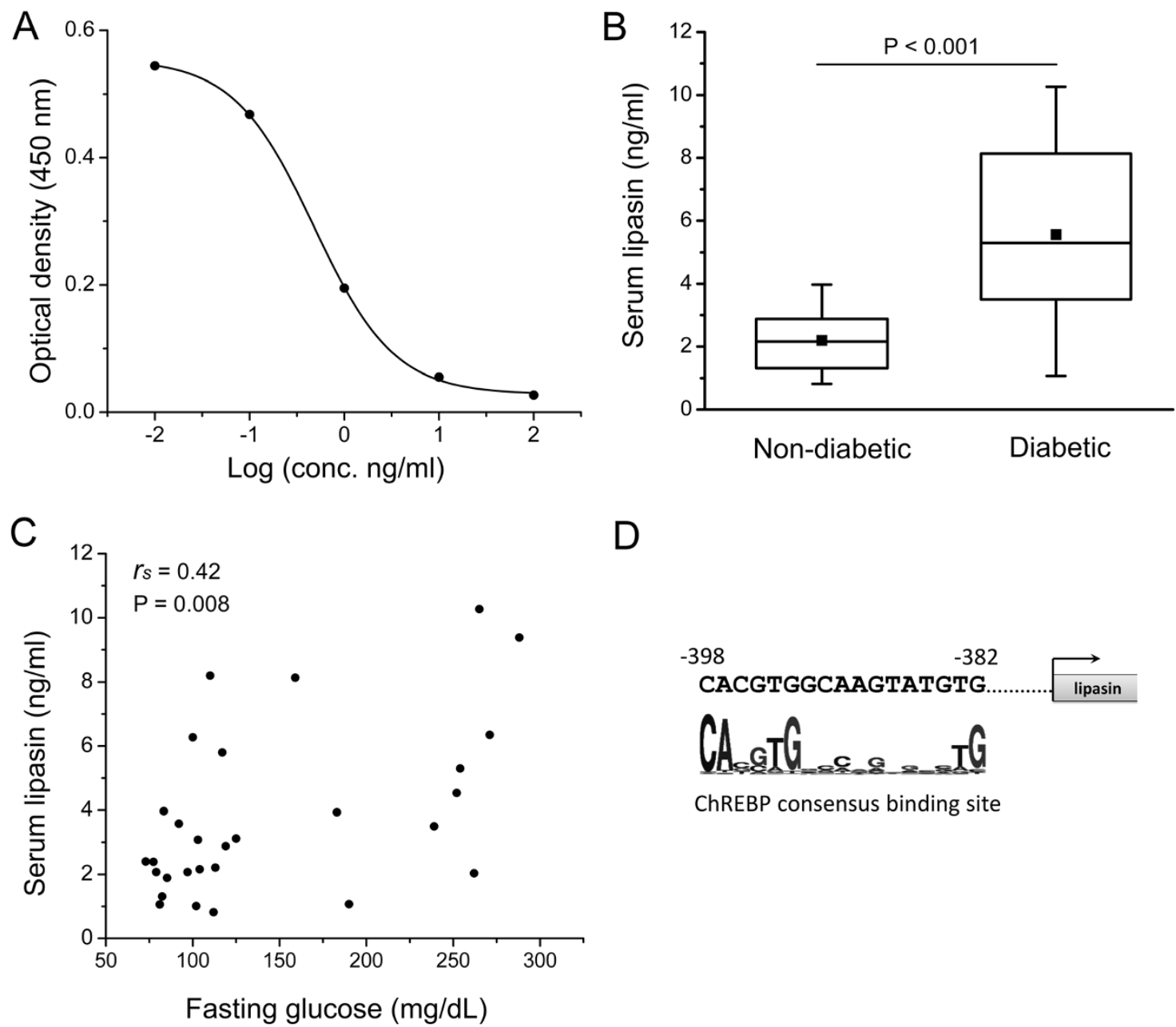

Figure 1 Serum levels of lipasin are elevated in patients with type 2 diabetes. A) Characterization of the standard curve for the lipasin ELISA kit. B) Serum lipasin levels are elevated in patients with type 2 diabetes. Box plot for lipasin levels in non-diabetic and diabetic subjects. Lipasin ELISA was performed using serum samples from overnight fasted non-diabetic $(n=15)$ and diabetic subjects $(n=14)$. Boxes represent the interquartile range between first and third quartiles, and the line (square) inside represents the median (mean). P values were obtained by performing Student $t$ tests. C) Correlation between serum lipasin and fasting glucose levels determined by Spearman's rank correlation. D) The promoter sequence of human lipasin and consensus binding site of ChREBP. The ChREBP consensus site is adapted from ref. 17.

\section{Results}

Because lipasin is present in the human circulation, it is critical to quantify its levels. We then performed an enzyme-linked immunosorbent assay (ELISA) for lipasin on human sera, and the kit was validated using a recombinant human lipasin protein (Fig. 1A). Fifteen non-diabetic and fourteen BMI- and age-matched diabetic human subjects were included. For non-diabetic and diabetic groups the mean age was $46.1 \pm 2.5$ and $48.2 \pm 2.6$ years, respectively, and the mean BMI was $26.2 \pm 1.2$ and $26.9 \pm 1.0 \mathrm{~kg} / \mathrm{m}^{2}$, respectively. There was no significant difference in age and BMI between groups, and also no significant differences in serum levels of triglycerides, total cholesterol, HDL cholesterol and LDL cholesterol (Table 1). The fasting glucose level in the non-diabetic subjects was $93.5 \pm 3.7 \mathrm{mg} /$ $\mathrm{dL}$, which was significant lower than that in the diabetic subjects $(201.1 \pm 18.2 \mathrm{mg} / \mathrm{dL}, \mathrm{P}<0.0001)$. The fasting insulin level in non-diabetic subjects $(6.1 \pm 0.5 \mu \mathrm{U} / \mathrm{dL})$ was significantly lower than that of diabetic patients $(10.5 \pm 1.3 \mathrm{U} / \mathrm{dL}, \mathrm{P}=0.002)$.

Because lipasin levels are sensitive to food intake, blood was drawn following an overnight fast. Serum samples were then used for ELISA analysis, which showed that the average serum lipasin concentration in the non-diabetic subjects was $2.19 \pm 0.24 \mathrm{ng} / \mathrm{mL}$. There was no significant difference in levels between male $(2.17 \pm 0.32 \mathrm{ng} / \mathrm{mL})$ and female subjects $(2.23 \pm 0.42 \mathrm{ng} / \mathrm{mL})$. In mice, lipasin, called betatrophin, was shown to be increased following a treatment using an insulin receptor antagonist to induce insulin resistance ${ }^{7}$. We therefore examined whether serum lipasin levels were increased in diabetic patients. Serum samples were collected from 14 patients with type 2 diabetes after an overnight fast and were assayed for

Table 1 | Clinical characteristics of subjects for examining lipasin levels in type 2 diabetes

\begin{tabular}{lccc} 
& Non-diabetic & Diabetic & Pvalue \\
\hline No. of subjects/women (N) & $15 / 9$ & $14 / 9$ & $\mathrm{NS}$ \\
BMl (kg/m $\left.{ }^{2}\right)$ & $26.2 \pm 1.2$ & $26.8 \pm 1.0$ & $\mathrm{NS}$ \\
Age (year) & $46.1 \pm 2.5$ & $49.2 \pm 2.6$ & $\mathrm{NS}$ \\
Glucose $(\mathrm{mg} / \mathrm{dL})$ & $93.5 \pm 3.7$ & $201.1 \pm 18.2$ & $<0.0001$ \\
$\mathrm{HAlc}(\%)$ & - & $9.2 \pm 0.3$ & $\mathrm{NA}$ \\
Triglycerides $(\mathrm{mg} / \mathrm{dL})$ & $145.5 \pm 28.5$ & $200.3 \pm 27.3$ & $\mathrm{NS}$ \\
Total cholesterol (mg/dL) & $176.5 \pm 9.4$ & $178.6 \pm 9.6$ & $\mathrm{NS}$ \\
$\mathrm{HDL}$ cholesterol $(\mathrm{mg} / \mathrm{dL})$ & $52.1 \pm 5.0$ & $45.3 \pm 5.9$ & $\mathrm{NS}$ \\
$\mathrm{LDL}$ cholesterol $(\mathrm{mg} / \mathrm{dL})$ & $98.1 \pm 7.3$ & $109.3 \pm 6.2$ & $\mathrm{NS}$ \\
Insulin $(\mu \mathrm{U} / \mathrm{dL})$ & $6.1 \pm 0.5$ & $10.5 \pm 1.3$ & 0.002 \\
\hline
\end{tabular}

Data are mean \pm SEM. Blood samples were collected following an overnight fast. Student $t$ test was performed to compare values between non-diabetic and diabetic subjects. NS, not significant. NA, not applicable. 

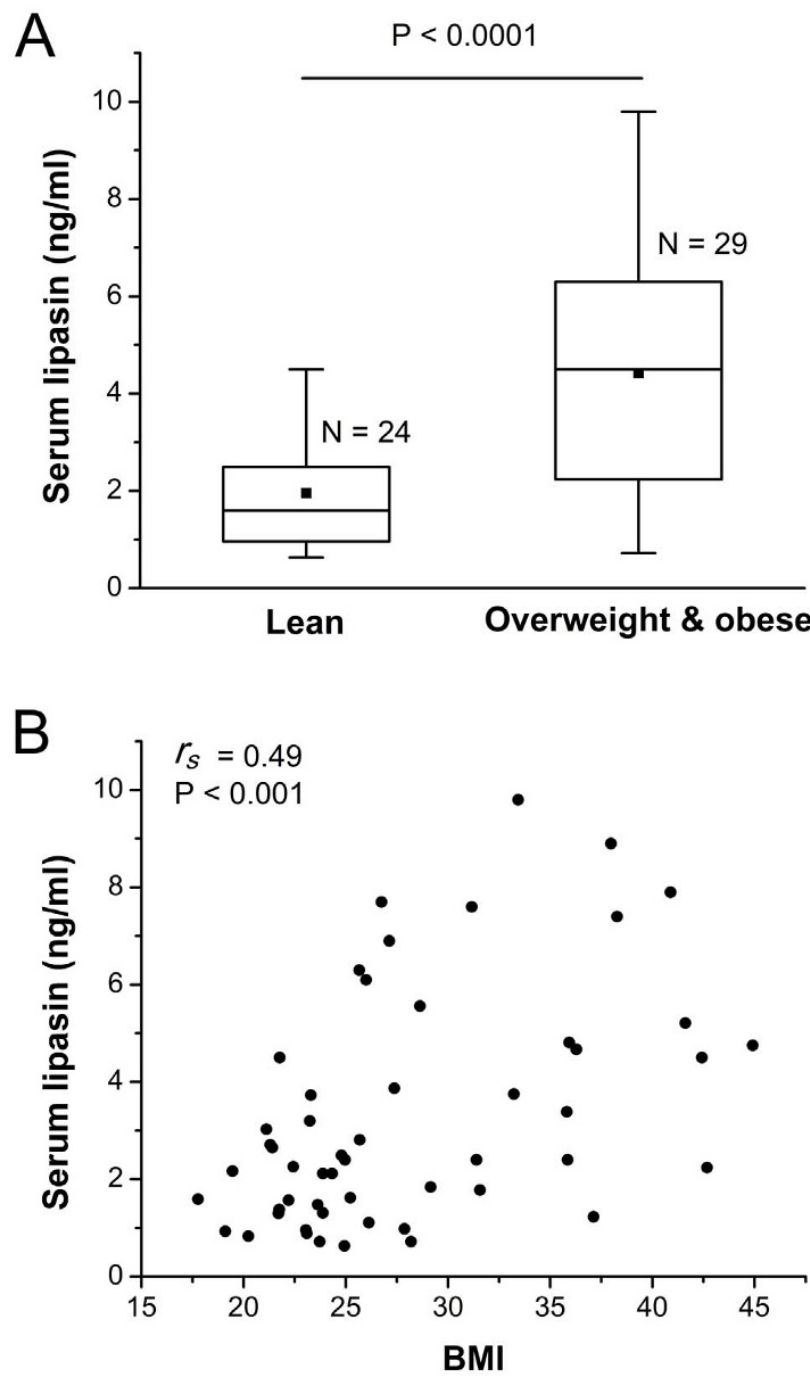

Figure $2 \mid$ Serum levels of lipasin are elevated in obesity, and are positively correlated to BMI. A) Serum lipasin levels are elevated in obesity. Serum lipasin levels were examined using ELISA. Box plot for lipasin levels in lean $(\mathrm{BMI}<25)$ and overweight or obese human subjects (BMI $\geq 25)$. Lipasin ELISA was performed using serum samples from overnight fasted lean $(n=24)$ and overweight or obese subjects $(n=29)$. Boxes represent the interquartile range between first and third quartiles, and the line (square) inside represents the median (mean). $\mathrm{P}$ values were obtained by performing Student $t$ tests. B) Serum lipasin levels are positively correlated with BMI determined by Spearman's rank correlation.

lipasin. The average serum lipasin level in the diabetic subjects was $5.56 \pm 0.73 \mathrm{ng} / \mathrm{mL}$, significantly higher than the level in non-diabetic subjects $(\mathrm{P}<0.001)$ (Fig. $1 \mathrm{~B})$.

Serum lipasin levels were increased in diabetic patients, who had high glucose levels, and therefore we examined whether there is a correlation between serum levels of lipasin and glucose. Indeed, fasting serum lipasin levels were positively correlated with glucose levels $\left(r_{s}=0.42, P=0.008\right.$, Fig. $\left.1 C\right)$ determined by Spearman's rank correlation coefficient. Lipasin levels appeared to be positively correlated insulin levels $\left(\mathrm{r}_{\mathrm{s}}=0.36, \mathrm{P}=0.048\right)$, but no significant correlation was observed between lipasin levels and those of triglycerides, total cholesterol, HDL cholesterol and LDL cholesterol.

Lipasin mRNA expression in liver was increased in mice with dietinduced obesity ${ }^{2}$. We therefore hypothesize that lipasin serum levels are increased in obesity. To test this hypothesis in humans, we examined serum lipasin levels in 53 male human subjects. Because serum lipasin is likely affected by food intake, serum was collected after

\begin{tabular}{|lc|}
\hline Table 2 | Nutritional composition of the provided meal \\
Total fat & $11 \mathrm{~g}$ \\
$\quad$ Saturated & $1 \mathrm{~g}$ \\
Polyunsaturated & 4.5 \\
Monounsaturated & 5 \\
Total carbohydrate & $50 \mathrm{~g}$ \\
Sucrose & $16 \mathrm{~g}$ \\
Protein & $13 \mathrm{~g}$ \\
Cholesterol & $10 \mathrm{mg}$ \\
Sodium & $240 \mathrm{mg}$ \\
Potassium & $420 \mathrm{mg}$ \\
\hline -350 calories. & \\
\hline
\end{tabular}

overnight fasting. The 53 human subjects had a BMI ranging from 17.8 to $44.9 \mathrm{~kg} / \mathrm{m}^{2}$. The 53 subjects were divided into two groups, one with $\mathrm{BMI}<25 \mathrm{~kg} / \mathrm{m}^{2}$ as lean group $(\mathrm{N}=24)$ and the other with BMI $\geq 25 \mathrm{~kg} / \mathrm{m}^{2}$ as the overweight or obese group $(\mathrm{N}=29)$; the mean serum lipasin levels in the former and latter were $1.96 \pm 0.20 \mathrm{ng} / \mathrm{ml}$ and $4.42 \pm 0.48 \mathrm{ng} / \mathrm{ml}$, respectively. Therefore, lipasin levels were more than doubled in the overweight group, compared to the lean group $\left(\mathrm{P}=6.4 \times 10^{-5}\right)$ (Fig. 2$)$. To test whether serum lipasin levels are positively correlated with BMI, we determined Spearman's rank correlation coefficient. Indeed, serum lipasin levels were positively correlated with BMI, $\mathrm{r}_{\mathrm{s}}=0.49, \mathrm{P}<0.001$. We therefore conclude that serum lipasin levels are increased in obesity and are positively correlated with BMI.

To test whether serum lipasin levels are altered following a meal, we recruited 12 non-diabetic human subjects. There were 8 male and 4 female subjects, with an average age of $36.7 \pm 3.3$ years and average BMI of $24.5 \pm 0.78 \mathrm{~kg} / \mathrm{m}^{2}$. All the subjects fasted overnight. The next day, a meal with 350 calories that was composed of $11 \mathrm{~g}$ of fat, $50 \mathrm{~g}$ of carbohydrate and $13 \mathrm{~g}$ of protein was provided (Table 2), and blood was drawn before and 2 hours after the meal. Serum lipasin levels before and after the meal were $1.88 \pm 0.29 \mathrm{ng} / \mathrm{mL}$ and $2.54 \pm$ $0.23 \mathrm{ng} / \mathrm{mL}$, respectively. There was a $35 \%$ increase in lipasin levels 2 hours following the meal (Fig. 3A) ( $\mathrm{p}=0.009$, paired Student $t$ test). Among the 12 subjects, 9 showed an increase following the meal (Fig. 3B). Therefore, serum lipasin levels were increased 2 hours following a defined meal.

\section{Discussion}

Type 2 diabetic patients exhibit hyperglycemia, hyperinsulinemia and hypertriglyceridemia. In non-diabetic persons, feeding increases blood glucose and stimulates pancreas secretion of insulin, which in the liver increases the synthesis of glycogen, fatty acids and triglycerides and suppresses gluconeogenesis. Insulin resistance is associated with a failure to suppress gluconeogenesis, but paradoxically, is associated with hypertriglyceridemia, rather than impaired triglyceride synthesis ${ }^{12,13}$. Because lipasin inhibits LPL, and thereby suppresses triglyceride clearance and increases serum triglycerides ${ }^{14}$, the increased serum lipasin levels in diabetes may potentially play a role in explaining the hypertriglyceridemia in type 2 diabetes. Nevertheless, in the current study, no correlation between fasting levels of lipasin and triglycerides was observed. This is possibly due to the confounding factors of glucose and BMI, because to examine correlation between lipasin and lipid levels, ideally, a cohort of subjects will need to have the following two characteristics: 1 ) a relatively wide range of lipid profile values and 2) without confounding factors, that is, comparable glucose levels and BMI.

Our results showing that serum lipasin is increased in diabetes and that its levels are positively correlated with glucose levels suggest that glucose may play a role in regulating lipasin expression. It has been well established that in mice lipasin mRNA is induced by feeding ${ }^{4,5,14}$; this is consistent with the current observation, because feeding 
A



B

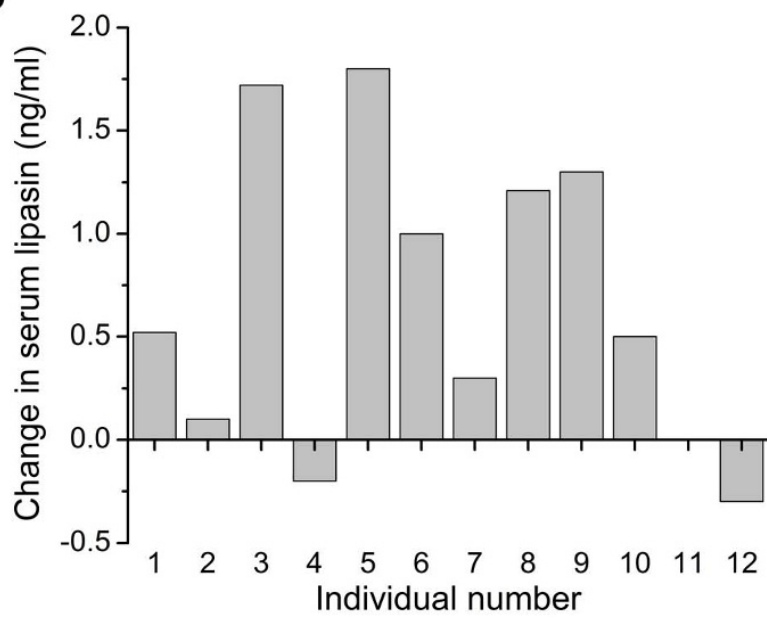

Figure 3 Serum levels of lipasin are increased 2 hours following a

defined meal. A) Serum lipasin levels were examined using ELISA. Serum samples were obtained from 12 lean human subjects after an overnight fast, without a meal or 2 hours following a defined meal. Refer to table 2 for meal nutritional composition. Each triangle denotes an individual, and the bars denote mean \pm SEM. P values were obtained by performing paired Student $t$ tests. B) Change in lipasin levels following the defined meal in each of the 12 individuals.

increases serum glucose. Consistently, the 14 diabetic patients had an average fasting glucose level of $201.1 \pm 18.2 \mathrm{mg} / \mathrm{dL}$, which is about 2 times higher than that of non-diabetic persons, $93.5 \pm 3.7 \mathrm{mg} / \mathrm{dL}$. It would be interesting to examine lipasin levels in diabetic patients treated to have glucose levels controlled into the normal range. Glucose regulates the expression of genes involved in energy homeostasis through ChREBP (carbohydrate response element-binding protein), a glucose-signaling transcription factor ${ }^{15,16}$, which binds to specific promoter sequences on the target gene known as charbohydrate responsive element (ChRE). Consistently, human lipasin promoter has a near-perfect ChREBP binding site from -398 to -382 of the transcriptional start site (Fig. 1D) and it has been shown that ChREBP indeed binds to the lipasin promoter in Hep G2 cells ${ }^{17}$. However, in the current study, insulin levels were increased in the diabetic patients, and therefore we cannot exclude the possibility that increased insulin was largely responsible for the elevated lipasin in the diabetic group. To prove the ChREBP regulation of lipasin expression, evidence regarding transcriptional regulation of lipasin and glucose needs to be obtained by future studies that use lipasin promoter deletion constructs and those containing mutations that abolish ChREBP binding.
During the past decades, the prevalence of obesity has grown to epidemic proportion, and this obesity epidemic is a major driving force in the increase in the prevalence of type 2 diabetes, because $90 \%$ of type 2 diabetes is attributable to obesity ${ }^{18}$. Another hallmark of obesity is increased triglyceride levels, as demonstrated by both epidemiological and controlled clinical trials ${ }^{19}$. It has been well established that lipasin is involved in the regulation of triglyceride metabolism $^{2,45,14}$. Lipasin KO mice display lower serum triglyceride levels ${ }^{6}$ and its overexpression dramatically increases triglyceride levels ${ }^{2,5}$. We here show that serum lipasin levels are increased in human obesity, and therefore, the increased lipasin may be a contributing factor for increased triglyceride levels in obesity. While the manuscript was being reviewed, we noticed a recent publication ${ }^{20}$ showing that circulating betatrophin does not correlate with glucose levels and BMI, contrasting to our results. The difference in betatrophin antibodies, being against the $\mathrm{N}$-terminus or the C-terminus, in ELISA kits used in Ref. 20 and the current study, respectively, likely explains the discrepancy and may reflect proteolytic status of lipasin/betatrophin. One limitation of the current study in examining postprandial lipasin levels is that only one time point was adopted in a limited number of subjects. It will be more informative in future studies to choose more time points with meals with different nutritional compositions in a relatively large number of subjects. Because lipasin is enriched in and secreted from the liver ${ }^{2,5,7}$, and because of its functional role in influencing whole-body metabolism, lipasin is likely a hepatokine.

In summary, the fasting serum lipasin level in non-diabetic lean subjects was about $2 \mathrm{ng} / \mathrm{mL}$, and was increased in patients with type 2 diabetes and obesity. Lipasin levels were increased 2 hours following a defined meal, and therefore, lipasin is a nutritionally-regulated hepatokine. With a dual role in triglyceride metabolism and glucose homeostasis, increased levels of lipasin in type 2 diabetes and obesity provide a potential mechanism in explaining hypertriglycemia in these two pathological conditions.

\section{Methods}

Study participants, samples and ELISA. To compare serum lipasin levels between patients with or without type 2 diabetes, 15 non-diabetic and 14 BMI- and agematched diabetic subjects were included in the study. To compare lipasin levels before and after a defined meal, 12 lean non-diabetic subjects were recruited. The purpose, nature and potential risks of the study were explained to all participants, and a written consent was obtained before their participation. After written informed consent was obtained, comprehensive screening tests were performed such as vitals, BMI, medical/health history, complete blood chemistry, CBC, HbAlc, and lipid profile. Serum samples of a total of 53 male human subjects, following an overnight fast, were included in the study to examine the relationship between lipasin levels and BMI, and these samples were collected by Valley Biomedical (Winchester, VA) by special collection to record body weight, height, age and race. The study protocol was approved by the Institutional Review Boards of Wayne State University School of Medicine and of the Detroit Medical Center, and all studies were carried out in accordance with the approved guidelines. Serum levels of human lipasin were determined by enzyme immunoassay kit (Phoenix Pharmaceuticals, Burlingame, CA) and the kit was validated using a human recombinant lipasin (EIAab Science Co, Wuhan, China).

Statistical analysis. Statistical significance was tested with two-tailed Student's $t$ tests, unless indicated otherwise. Paired Student $t$ tests were performed to compare lipasin levels before and after the defined meal. Correlations between serum lipasin levels and other parameters, including BMI and glucose levels, were determined by Spearman's rank correlation. The differences were considered statistically significant if $\mathrm{P}<0.05$.

1. Eckel, R. H., Grundy, S. M. \& Zimmet, P. Z. The metabolic syndrome. Lancet 365, 1415-1428 (2005).

2. Zhang, R. Lipasin, a novel nutritionally-regulated liver-enriched factor that regulates serum triglyceride levels. Biochem Biophys Res Commun 424, 786-92 (2012).

3. Fu, Z., Yao, F., Abou-Samra, A. B. \& Zhang, R. Lipasin, thermoregulated in brown fat, is a novel but atypical member of the angiopoietin-like protein family. Biochem Biophys Res Commun 430, 1126-31 (2013).

4. Ren, G., Kim, J. Y. \& Smas, C. M. Identification of RIFL, a novel adipocyteenriched insulin target gene with a role in lipid metabolism. Am J Physiol Endocrinol Metab 303, E334-51 (2012). 
5. Quagliarini, F. et al. Atypical angiopoietin-like protein that regulates ANGPTL3. Proc Natl Acad Sci U S A 109, 19751-6 (2012).

6. Wang, Y. et al. Mice lacking ANGPTL8 (Betatrophin) manifest disrupted triglyceride metabolism without impaired glucose homeostasis. Proc Natl Acad Sci U S A (2013).

7. Yi, P., Park, J. S. \& Melton, D. A. Betatrophin: a hormone that controls pancreatic beta cell proliferation. Cell 153, 747-58 (2013).

8. Tang, T. et al. A mouse knockout library for secreted and transmembrane proteins. Nat Biotechnol 28, 749-55 (2010).

9. Teslovich, T. M. et al. Biological, clinical and population relevance of 95 loci for blood lipids. Nature 466, 707-13 (2010).

10. Peloso, G. M. et al. Association of low-frequency and rare coding-sequence variants with blood lipids and coronary heart disease in 56,000 whites and blacks. Am J Hum Genet 94, 223-32 (2014).

11. Espes, D., Lau, J. \& Carlsson, P. O. Increased circulating levels of betatrophin in individuals with long-standing type 1 diabetes. Diabetologia 57, 50-3 (2013).

12. Brown, M. S. \& Goldstein, J. L. Selective versus total insulin resistance: a pathogenic paradox. Cell Metab 7, 95-6 (2008).

13. Biddinger, S. B. et al. Hepatic insulin resistance is sufficient to produce dyslipidemia and susceptibility to atherosclerosis. Cell Metab 7, 125-34 (2008).

14. Zhang, R. \& Abou-Samra, A. B. Emerging roles of Lipasin as a critical lipid regulator. Biochem Biophys Res Commun 432, 401-5 (2013).

15. Uyeda, K. \& Repa, J. J. Carbohydrate response element binding protein, ChREBP, a transcription factor coupling hepatic glucose utilization and lipid synthesis. Cell Metab 4, 107-10 (2006).

16. Filhoulaud, G., Guilmeau, S, Dentin, R, Girard, J. \& Postic, C. Novel insights into ChREBP regulation and function. Trends Endocrinol Metab 24, 257-68 (2013).

17. Jeong, Y. S. et al. Integrated expression profiling and genome-wide analysis of ChREBP targets reveals the dual role for ChREBP in glucose-regulated gene expression. PLoS One 6, e22544 (2011).

18. Hossain, P., Kawar, B. \& El Nahas, M. Obesity and diabetes in the developing world--a growing challenge. N Engl J Med 356, 213-5 (2007).
19. Miller, M. et al. Triglycerides and cardiovascular disease: a scientific statement from the American Heart Association. Circulation 123, 2292-333 (2011).

20. Fenzl, A. et al. Circulating betatrophin correlates with atherogenic lipid profiles but not with glucose and insulin levels in insulin-resistant individuals.

Diabetologia, in press (2014).

\section{Acknowledgments}

We thank Dr. M.A. Abdul-Ghani for stimulating discussions. The present work was supported in part by a fund (176412) from Wayne State University to R.Z.

\section{Author contributions}

R.Z. designed the study, analyzed the data and drafted the manuscript. B.S. and A.B.-S. analyzed the data and revised the manuscript. Z.F. and F.B. performed the experiments. F.B and A.F. participated in human sample collection.

\section{Additional information}

Disclosure statement: the authors have nothing to disclose.

Competing financial interests: The authors declare no competing financial interests.

How to cite this article: Fu, Z.Y. et al. Elevated circulating lipasin/betatrophin in human type 2 diabetes and obesity. Sci. Rep. 4, 5013; DOI:10.1038/srep05013 (2014).

This work is licensed under a Creative Commons Attribution-NonCommercialShareAlike 3.0 Unported License. The images in this article are included in the article's Creative Commons license, unless indicated otherwise in the image credit if the image is not included under the Creative Commons license, users will need to obtain permission from the license holder in order to reproduce the image. To view a copy of this license, visit http://creativecommons.org/licenses/by-nc-sa/3.0/ 